\title{
Percepções de professores universitários brasileiros sobre as virtudes mais valorizadas no exercício da docência
}

\author{
Marcella Bastos Cacciari \\ Faculdade Multivix - São Mateus - ES - Brasil \\ Valeschka Martins Guerra \\ Universidade Federal do Espirito Santo - Vitória - ES - Brasil \\ Priscilla Oliveira Martins-Silva \\ Universidade Federal do Espirito Santo - Vitória - ES - Brasil \\ Clarisse Lourenço Cintra \\ Universidade Federal do Espirito Santo - Vitória - ES - Brasil \\ Naiara Ferreira Vieira Castello \\ Universidade Federal do Espirito Santo - Vitória - ES - Brasil
}

\section{Resumo}

Disseminam-se atualmente em todo o mundo artigos que colocam em pauta a forma com que os professores sentem e vivenciam a profissão. 0 presente estudo buscou investigar as virtudes necessárias para ser um bom professor e o quanto os participantes percebem que tais características os descrevem como profissionais. Para tanto, utilizou-se o método de pesquisa misto, de forma a contemplar aspectos quantitativos e qualitativos dos fenômenos investigados. Participaram deste estudo 214 professores universitários brasileiros, que responderam um questionário formado por questões sociodemográficas e duas perguntas abertas sobre as virtudes do bom professor. A análise textual foi realizada a partir do software IRAMUTEQ e representada graficamente pela análise de similitude. De acordo com os resultados obtidos, as virtudes mais valorizadas no exercício docente foramconhecimento, temperança, justiça e humanidade. Estes resultados ajudam a pensar nas habilidades e competências exigidas na vida acadêmica, assim como na avaliação das práticas docentes.

Palavras-chave: Virtudes; professores universitários; psicologia positiva.

\section{Perceptions of Brazilian university professors on the virtues most valued in}

\section{the teaching profession}

\begin{abstract}
Articles are now being disseminated throughout the world that highlight the way in which teachers feel and experience the profession.The present study investigated the virtues necessary to be a good teacher and how much the participants perceive that these characteristics describe them as professionals. For this, the mixed research method was used, in order to contemplate quantitative and qualitative aspects of the investigated phenomena. A total of 214 Brazilian university professors participated in this study, who answered a questionnaire formed by sociodemographic questions and two open questions about the virtues of the good teacher. The textual analysis was performed from the IRAMUTEQ software and graphically represented by similarity analysis. According to the results obtained, the virtues most valued in the teaching exercise were knowledge, temperance, justice and humanity. These results help to think about the skills and competences required in academic life, as well as the evaluation of teaching practices.
\end{abstract}

Keywords: virtues; university professors; positive psychology.

\section{Percepciones de profesores universitarios brasileños sobre las virtudes más}

\section{valoradas en el ejercicio de la docencia}

\section{Resumen}

Se diseminan actualmente en todo el mundo artículos que colocan en pauta la forma con que los profesores sienten y vivencian la profesión. El presente estudio buscó investigar las virtudes necesarias para ser un buen profesor y lo cuanto los participantes perciben que tales características los describen como profesionales. Para tanto, se utilizó el método de investigación mixta, de forma a contemplar aspectos cuantitativos y cualitativos de los fenómenos investigados. Participaron de este estudio 214 profesores universitarios brasileños, que respondieron un cuestionario formado por cuestiones sociodemográficas y dos preguntas abiertas sobre las virtudes del buen profesor. El análisis textual fue realizado a partir del software IRAMUTEQ y representado gráficamente por el análisis de similitud. De acuerdo conlos resultados obtenidos, las virtudes más valoradas en el ejercicio docente fueron conocimiento, templanza, justicia y humanidad. Estos resultados ayudan a pensar en las habilidades y competencias exigidas en la vida académica, así como en la evaluación de las prácticas docentes.

Palabras clave: Virtudes; profesores universitarios; psicología positiva. 


\section{Introdução}

Disseminam-se atualmente em todo o mundo estudos que colocam em pauta a forma com que os professores sentem e vivenciam a profissão, e não apenas os métodos pedagógicos e didáticos utilizados em sala de aula. Busca-se privilegiar o espaço que o trabalho ocupa na vida dos docentes, considerando as implicações para a saúde física e psicológica dos trabalhadores (Pocinho \& Perestrelo, 2011; Hakanen, Bakker, \& Schaufeli, 2006; Horn, Taris, Schaufeli, \& Schreurs, 2004). Dessa forma, o pano de fundo dos estudos atuais tem como referência a importância do trabalho dentro da história de vida dos professores.

De acordo com Hannah Arendt (2007), o trabalho é uma das atividades humanas fundamentais e apresenta como principal característica a produção de objetos artificiais, que emprestam um caráter de permanência à vida, em contraposição à efemeridade do mundo natural. De tal modo, o trabalho é responsável pela produção de sentido e continuidade da existência humana, construindo ambientes familiares e possibilitando a manutenção das identidades individuais e do grupo. A importância do trabalho na vida das pessoas e na maneira como elas interpretam suas próprias experiências, demanda melhor compreensão acerca das vivências dos trabalhadores que se encontram exatamente no ponto central da dinâmica entre o mundo do conhecimento e o mundo do trabalho.

A construção de um panorama geral sobre a profissão docente revela estudos que enfatizam os aspectos negativos da profissão, como estresse ocupacional (Araújo, Graça, \& Araújo, 2003) e burnout (Sousa \& Mendonça, 2009; Garcia \& Benevides-Pereira, 2003), além de contemplar o ambiente institucional educacional e toda a sua complexidade, incluindo as pressões por resultados, as responsabilidades e as competências exigidas para atuar na área acadêmica (Silva, Damásio, \& Melo, 2009; Rocha \& Sarriera, 2006). No entanto, um novo conjunto de pesquisas têm buscado enfatizar também os fatores positivos presentes na profissão (Pocinho \& Perestrelo, 2011; Silva, Damásio, \& Melo, 2009; Amparo, Galvão, Cardenas, \& Koller, 2008; Rocha \& Sarriera, 2006).

Nesse sentido, Pocinho e Perestrelo (2011) estabelecem em um ensaio teórico a relação entre a síndrome de burnout e os construtos de engagement (engajamento) e coping (estratégias de enfrentamento) na docência. Segundo a revisão de literatura das autoras portuguesas, aqueles professores que utilizam estratégias de escape ou fuga diante de situações estressantes, tendem a ter maiores índices de burnout e insatisfação com o emprego. Todavia, os professores que relatam o uso de estratégias positivas de coping e busca de resolução de problemas demonstram maior realização profissional. Dessa maneira, as estratégias positivas mostram-se comoum fator de promoção do engajamento que, por conseguinte, funciona como uma das possíveis variáveis facilitadoras para o sucesso acadêmico dos alunos.

Silva e cols. (2009) apontam o alto nível de estresse ocupacional na amostra estudada, composta por 517 professores escolares da cidade de Campina Grande/PB. Tais professores, entretanto, apresentaram altos índices de compreensão do seu sentido de vida. Desse modo, o sentido de vida foi relacionado à mediação de eventos adversos e à melhor adaptação ao ambiente de trabalho. Isto pôde ser explicado a partir da realização existencial ligada às atividades docentes, que ajudaria no processo de adaptação ao ambiente de trabalho estressor e na modificação/criação de estratégias de enfrentamento mais eficazes.

Amparo, Galvão, Cardenas e Koller (2008) indicam a importância da relação professor-aluno, como parte do resultado de um extenso levantamento de dados junto a 852 jovens em situação de risco, moradores de regiões administrativas do Distrito Federal. Os resultados obtidos revelam que $60 \%$ dos participantes afirmam gostar dos professores, porém, apenas 40,5\% declaram poder contar com eles, e somente $37,7 \%$ confiam em seus educadores. Os autores alertam para a necessidade da construção de uma cultura de confiança nas instituições de educação, que ultrapasse o vínculo emocional professor-aluno, e invista em relações mais profundas e consistentes, com o intuito de formar cidadãos mais conscientes de si e do mundo.

Rocha e Sarriera (2006), por sua vez, retratam a necessidade de se identificar as variáveis de impacto sobre a saúde dos professores. Deste modo, o sexo dos participantes, a prática religiosa e a quantidade de horas de trabalho foram variáveis mais relacionadas aos níveis de saúde dos participantes. No entanto, esses autores sugerem que precisam ser produzidos mais estudos sobre as características positivas do trabalho, de forma a identificar os aspectos que possam contribuir para uma melhoria no quadro geral de saúde dos trabalhadores.

Nesse contexto, a Psicologia Positiva (Seligman \& Csikszentmihalyi, 2000) consolida-se como uma abordagem teórica e metodológica útil. McGovern e Miller (2008), por exemplo, recomendam o uso de uma ferramenta que integra a percepção das próprias virtudes por parte do professor, com uma lista de comportamentos pedagógicos para o desenvolvimento de competências na docência. A "Lista de comportamentos do professor" oferece parâmetros para a identificação de características pessoais positivas dos docentes e seu aproveitamento no contexto profissional (Keeley, Smith, \& Buskist, 2006). Isso permite aos professores avaliar o seu próprio desempenho profissional, além de facilitar a percepção de suas virtudes pessoais, bem como sua utilização em sala de aula.

Observa-se, então, que a Psicologia Positiva (Seligman \& Csikszentmihalyi, 2000) pode ser incluídano estudo dos aspectos psicológicos presentes no desempenho da profissão docente e relevantes para a saúde mental dos professores. No presente estudo serão investigadas, por meio do quadro teórico da Psicologia Positiva, as virtudes necessárias para ser um bom professor a partir da perspectiva do docente, assim como, o quanto os docentes acreditam apresentar tais virtudes. Este estudo mostra-se relevante no âmbito científico, mais especificamente na área da Psicologia Educacional, por permitir uma discussão acerca do impacto qualitativo da idealização dos professores em seu 
comportamento cotidiano e na sua rotina como profissionais da educação.

\section{A Psicologia Positiva}

Os fenômenos positivos entraram em voga como objeto de estudo nos últimos anos, no Brasil e no mundo, decorrentes do advento da Psicologia Positiva, proposta por Martin Seligman, quando em 1998, assumiu a presidência da American Psychological Association (APA). Observa-se uma mudança gradual na abordagem dada ao desenvolvimento humano nos estudos brasileiros mais recentes, refletindo a importância da crença no potencial do ser humano, e em sua capacidade para se desenvolver de forma plena (Pureza, Kuhn, Castro, \& Lisboa, 2012; Dell'Aglio, Koller, \& Yunes, 2011).

Segundo Paludo e Koller (2007), a relevância do enfoque positivo encontra base na promoção da saúde, nos fatores de proteção e prevenção. Afinal, após a conquista de grandes avanços na área da psicopatologia, seja em tratamentos clínicos, intervenções ou modelos teóricos, emerge a oportunidade para o estudo do funcionamento humano positivo. As autoras enfatizam temas como virtudes, forças de caráter, habilidades em contextos de resiliência, experiências e relações positivas no esclarecimento sobre quais mecanismos contribuem para a saúde física, o bem-estar subjetivo e o florescimento de grupos e instituições. Podem ser acrescentados também outros construtos, tais comofelicidade, otimismo, esperança e experiência ótima (flow), conforme as sugestões de Neto e Marujo (2012).

$\mathrm{Na}$ busca de apreender e explicar o sistema de potencialidades refletido nos comportamentos humanos, Peterson e Seligman (2004) elencaram as seis principais virtudes dentro da lógica positiva. Juntamente com tais virtudes, os autores também definiram as forças de caráter que podem ser consideradas como expressões dessas virtudes ou habilidades, e que podem ser exercitadas para se alcançar as virtudes correspondentes, assim distribuídas: 1) Sabedoria/ Conhecimento, expressa e exercitada pelas forças de criatividade, curiosidade, mente aberta, e amor por aprender; 2) Coragem, expressa e exercitada pelas forças de bravura, persistência, integridade, e vitalidade; 3) Humanidade, expressa e exercitada pelas forças de amor, gentileza, e inteligência social; 4) Justiça, expressa e exercitada pelas forças de cidadania, equidade, e liderança; 5) Temperança, expressa e exercitada pelas forças de piedade,humildade, prudência e autocontrole; e 6) Transcendência, expressa e exercitada pelas forças de apreciação da beleza, gratidão, esperança, humor e espiritualidade.

No estudo longitudinal de Wood, Linley, Maltby, Kashdan e Hurling (2011), a utilização das forças de caráter pôde predizer altos níveis de autoestima, vitalidade e afetos positivos. Já no levantamento de Gander, Proyer, Ruch e Wyss (2012) foi sublinhada a relevância da utilização das forças de caráter em ambientes de trabalho para o aumento de comportamentos saudáveis, relacionados principalmente ao entusiasmo, persistência, esperança e curiosidade.
Diante da proposta teórica da Psicologia Positiva, e com o objetivo de considerar as características positivas da vida docente, a presente pesquisa constituiu-se em uma investigação sobre as virtudes necessárias para ser um bom professor. Para isso, a presente pesquisa investigou a partir da perspectiva do docente quais virtudes são necessárias ao bom professor e o quanto acreditam apresentar tais virtudes.

\section{Método}

O presente estudo utilizou o método de pesquisa misto, como proposto por Creswell (2013), de forma a contemplar aspectos quantitativos e qualitativos dos fenômenos psicológicos abordados. Para tanto, foram realizados procedimentos simultâneos que buscaram a convergência entre os dois tipos de dados, quantitativos e qualitativos, tanto durante a fase de coleta quanto na fase de interpretação dos resultados (Creswell, 2013), conforme detalhado a seguir.

\section{Participantes}

Participaram do estudo 214 professores de ensino superior, sendo $44,4 \%$ do sexo masculino e $55,6 \%$ do sexo feminino, com idades variando entre 22 e 65 anos $(\mathrm{M}=$ 39,21; DP = 9,77). Do total de participantes, 73,8\% lecionam em universidades públicas e $37,4 \%$ em instituições particulares, com um tempo médio de trabalho de 9,6 anos (DP $=7,83$ ). Com relação à localização geográfica, $63,6 \%$ dos participantes viviam na região Sudeste, $25,7 \%$ no Nordeste, $5,1 \%$ no Sul, $2,8 \%$ no Norte e $2,8 \%$ na região Centro-Oeste. O principal critério para a escolha dos participantes foi o fato dos mesmos atuarem como professores de ensino superior no período da coleta de dados da pesquisa.

\section{Instrumento}

Foi utilizado um questionário on-line com o objetivo de atingir o maior número possível de indivíduos dentro do perfil selecionado para a pesquisa, em todo o Brasil, economizando tempo e recursos previstos para a pesquisa (Freitas, Janissek-Muniz, \& Moscarola, 2004). O questionário era composto da seguinte forma: (1) questões sociodemográficas, tais como sexo, idade, área de formação e de ensino; e (2) duas questões abertas sobre as qualidades ideais do professor: "Aponte as principais características/virtudes para ser um bom professor:" e "Quanto você se considera dentro desse ideal?".

\section{Procedimento de coleta de dados}

Para a coleta de dados o questionário foi disponibilizado no Google Drive e divulgado entre professores de universidades públicas e particulares via e-mail, listas de correspondências de faculdades e sindicatos (mailing lists), 
e redes sociais. Após clicar no link da pesquisa, o participante era direcionado ao Termo de Consentimento Livre e Esclarecido (TCLE), que o informava sobre os objetivos do estudo, e o caráter voluntário e confidencial dos dados. Para continuar respondendo o questionário, o participante deveria concordar com sua participação. Caso contrário, o participante era apresentado a uma página que continha uma mensagem de agradecimento.

\section{Procedimento de análise de dados}

Os dados foram analisados por meio do software IRAMUTEQ (Ratinaud, 2009). Trata-se de um software que faz análises estatísticas básicas e multivariadas sobre corpus textuais e tabelas indivíduos/palavras, organizando a distribuição do vocabulário de forma clara e compreensível (Camargo \& Justo, 2013). Neste caso, foi realizada a análise de similitude, que permite a identificação da estrutura central do corpus, assim como das partes comuns e específicas dos textos através das variáveis descritivas localizadas pelo software, realizando um um cruzamento entre todos os termos que mantém alguma relação entre si, ilustrados na denominada árvore máxima (Ratinaud \& Marchand, 2012). Para tanto, os dados foram organizados em dois bancos de dados, sendo cada banco composto pelo conjunto de respostas obtido pelas duas questões do instrumento. A análise de similitude permitiu a construção da árvore máxima com as coocorrências, a identificação das palavras mais citadas e as indicações sobre sua associação. O critério para inclusão na análise eram palavras citadas dez vezes ou mais, conforme sugerido por Wachelke e Wolter (2011).

\section{Análise de riscos e procedimentos éticos}

Este trabalho foi desenvolvido com respeito às normas e exigências éticas vigentes na Resolução n 466/12, do Conselho Nacional de Saúde, que incluem os direitos garantidos aos participantes, como: a) participação voluntária; b) esclarecimento dos objetivos de pesquisa e procedimentos; c) direito à interrupção da participação sem quaisquer prejuízos; e d) garantia de anonimato. O projeto original foi submetido e aprovado pelo Comitê de Ética em Pesquisa (CEP) local sob o protocolo CAAE 27708214.2.0000.5542. Avaliou-se que o estudo proposto envolveu riscos mínimos aos participantes

\section{Resultados}

As análises de similitude originaram dois gráficos principais. O primeiro gráfico refere-se às respostas para a questão "Aponte as principais características/virtudes para ser um bom professor" e reflete aquelas características mais citadas pelos participantes para ser um bom profissional na área acadêmica. Estas conexões contextualizam o discurso dos professores universitários acerca das virtudes para o exercício docente (Figura 1). O primeiro corpus analisado é composto por um conjunto de 206 textos, com conteúdo monotemático, e focado nas virtudes mais citadas pelos professores. Este material foi dividido em 251 segmentos

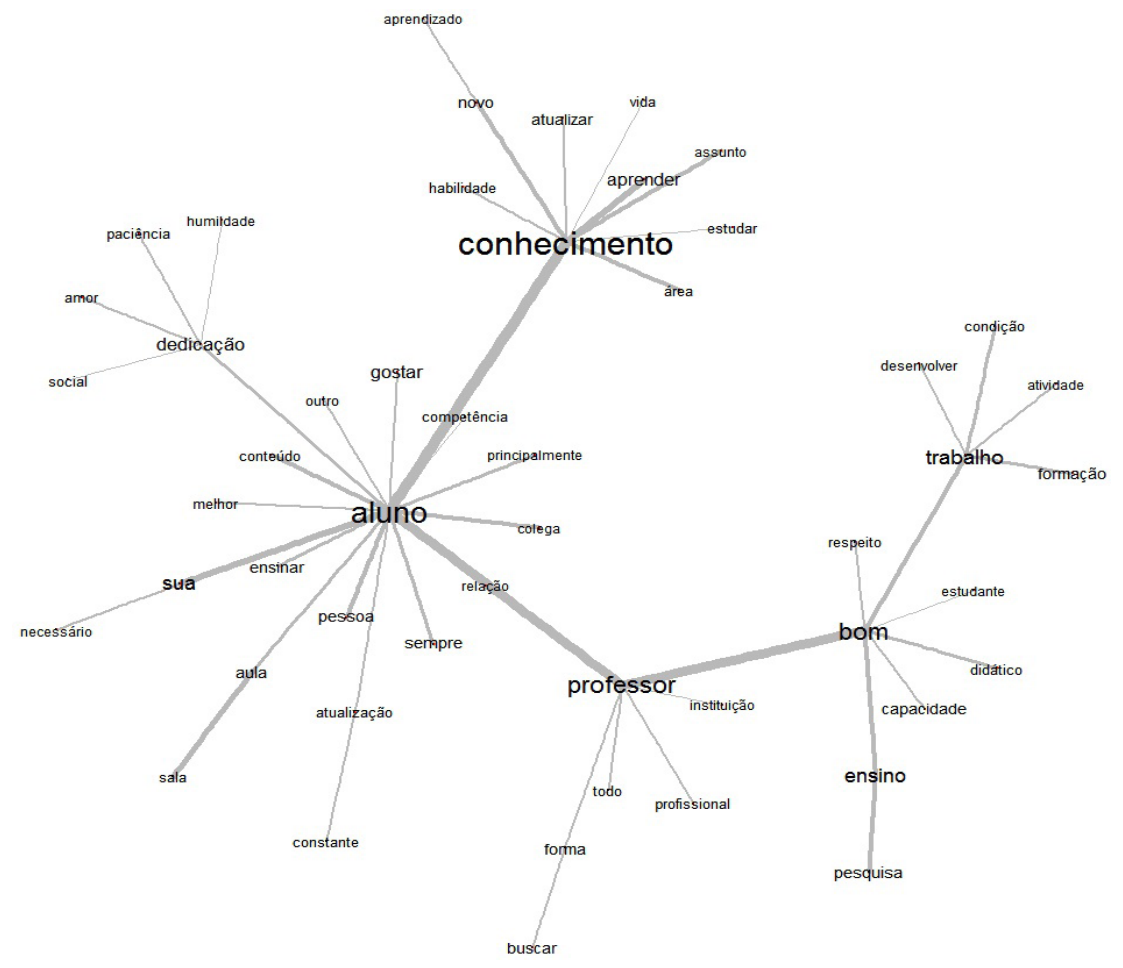

Figura 1. Virtudes do bom professor. 
de texto, com 5420 ocorrências, 1404 formas identificadas de palavras, e freqüência de Hapax857 (sendo 61,04\% das formas e $15,81 \%$ das ocorrências).

Neste gráfico, existe uma relação principal entre os troncos de similitudes das palavras-chave: a) conhecimento e aluno; b) alunoededicação; c) aluno e professor; d) professor e bom; e) bom e trabalho. São conexões fortes, que revelam a ligação contida entre tais palavras no discurso dos participantes.

A partir da palavra-chave conhecimento, a mais citada do corpus tendo sido apresentada 83 vezes pelos participantes, foram destacadas palavras como "aprender", "aprendizado", "atualizar", "estudar", "habilidade”, "novo", "assunto", "vida" e "área". Os recortes operados nas falas demonstram a maneira como o conhecimento foi definido nas respostas: "Estar disposto a estar atualizado, ter conhecimento amplo e não apenas o conhecimento específico daquilo que leciona, ter capacidade de passar o conhecimento que possui e estar disposto e disponível para atender os alunos nas suas necessidades de aprendizagem" (Part. 42, sexo fem., univ. pública, 37 anos); "Muito conhecimento, estudar constantemente, respeitar os outros, conhecer seus limites e lutar para superá-los" (Part. 106, sexo masc., univ. pública, 60 anos); "Atualização, conhecimento, paixão e humanidade” (Part. 197, sexo fem., univ. particular, 55 anos).

A palavra-chave aluno apresentou em seu entorno palavras como "ensinar", "pessoa", "relação", "conteúdo", "atualização/constante", "sala/aula", "competência" e "gostar". Os recortes da pesquisa refletem a palavra-chave aluno, bem como suas ligações com as palavras-chave conhecimento e dedicação: "... compromisso do professor com a formação do cidadão, com a aprendizagem do aluno, tendo bom senso para ensinar o que se propõe" (Part. 87, sexo masc., univ. particular, 38 anos); "Ter a mente aberta para poder lidar com a variabilidade de alunos. Gostar de ensinar. Ter curiosidade para sempre buscar novas formas de trabaIhar com os alunos e orientandos" (Part. 92, sexo fem., univ. pública, 29 anos); "Conhecimento e atualização cotidiana sobre o tema que ministra. Relacionamentos interpessoais saudáveis com os alunos. Métodos de ensino diversificados" (Part. 147, sexo masc., univ. pública, 29 anos).

A palavra-chave dedicação demonstrou uma relação forte com a palavra-chave aluno. As palavras que apareceram em destaque no seu tronco de similitude foram "humildade", "paciência", "amor "e "social".

Alguns exemplos esclarecem a forma como a dedicação foi relatada no discurso dos participantes: "É necessário gostar de aprender sobre uma determinada área e se dedicar a isso ... ter paciência com as dificuldades dos alunos e humildade para assumir erros e dizer que não sabe uma coisa, mas buscar aprender logo em seguida" (Part. 155, sexo fem., univ. pública, 41 anos); "Amor e dedicação. Muita paciência e ter a serenidade de compreender que estamos diante de turmas cada vez mais imaturas e mal preparadas para a vida e estudos avançados ..." (Part. 183, sexo fem., univ. particular, 39 anos); "Amar o que faz, e sentir prazer em ensinar pensando que pode aprender um pouco mais sempre" (Part. 185, sexo masc., univ. pública, 41 anos).

Nesse contexto, a palavra-chave aluno também apresentou uma ligação forte com a palavra-chave professor. Tal conjunto foi constituído pelas palavras "forma", "profissional", "instituição", "buscar" e "todo".

Algumas falas que caracterizam o professor na relação com o aluno são expostas a seguir: “... busca constante por novas informações, formação continuada, busca por desafios através de projetos realizados em sala de aula, pesquisa e extensão" (Part. 08, sexo fem., univ. pública, 29 anos); "Busca constante pelo saber, empatia com as diferentes realidades dos alunos, ser idealista no sentido de querer modificar o mundo ..." (Part. 14, sexo masc., univ. particular, 41 anos); "Entender que a relação professor e aluno é modelar, ter uma prática docente reflexiva e buscar a coerência entre o discurso e os atos" (Part. 158, sexo fem., univ. pública, 47 anos).

Já a palavra-chave bom, conectada diretamente ao professor, aparece ao lado das palavras "ensino/pesquisa", "capacidade", "didático(a)", "estudante" e "respeito". Pode-se constatar isso em outros trechos das respostas: "... respeito ao professor tanto dos alunos como da instituição, respeito ao aluno tanto do professor como da instituição, compromisso do professor com a formação do cidadão ..." (Part. 87, sexo masc., univ. particular, 38 anos); "É fundamental ser um bom exemplo aos alunos, ser capaz de mostrar a eles novas formas de pensar" (Part. 150, sexo fem., univ. pública, 29 anos); "Um bom professor, deve ser estudioso, gostar do que faz, ter habilidades de comunicação, bom relacionamento com os estudantes, estar sempre atualizado, buscar novas formas de didática ..." (Part. 175, sexo fem., univ. pública, 31 anos).

De outra maneira, a palavra-chave trabalho foi acompanhada pelas palavras "desenvolver", "condição", "atividade" e "formação". Nas falas dos participantes, esse grupo de palavras foi retratado da seguinte forma: "Ter prazer no que faz. Ter melhores condições de trabalho" (Part. 72, sexo fem., univ. particular, 31 anos); "Desenvolver todas as competências possiveis de forma a atender todas as necessidades da clientela atendida e desenvolver um bom trabalho para que se sinta pessoalmente satisfeito" (Part. 116, sexo fem., univ. pública e particular, 31 anos); "Acho que o professor precisa fazer ensino, pesquisa, e extensão, e poder desenvolver o trabalho de acordo com a sua formação" (Part. 179, sexo fem., univ. pública, 50 anos).

No segundo gráfico estão contidas as respostas para a questão "O quanto você se considera próximo desse ideal?". As respostas indicam o quanto os participantes acreditam possuir as virtudes citadas e estar dentro do ideal do bom professor (Figura 2). O segundo corpus analisado constitui-se em um conjunto de 206 textos, com conteúdo monotemático e reflete a percepção subjetiva dos professores universitários sobre suas próprias virtudes docentes. Este material foi dividido em 263 segmentos de texto, com 6010 ocorrências, 1492 formas identificadas de palavras, e freqüência de Hapax912 (sendo $61,13 \%$ das formas e $15,17 \%$ das ocorrências). 


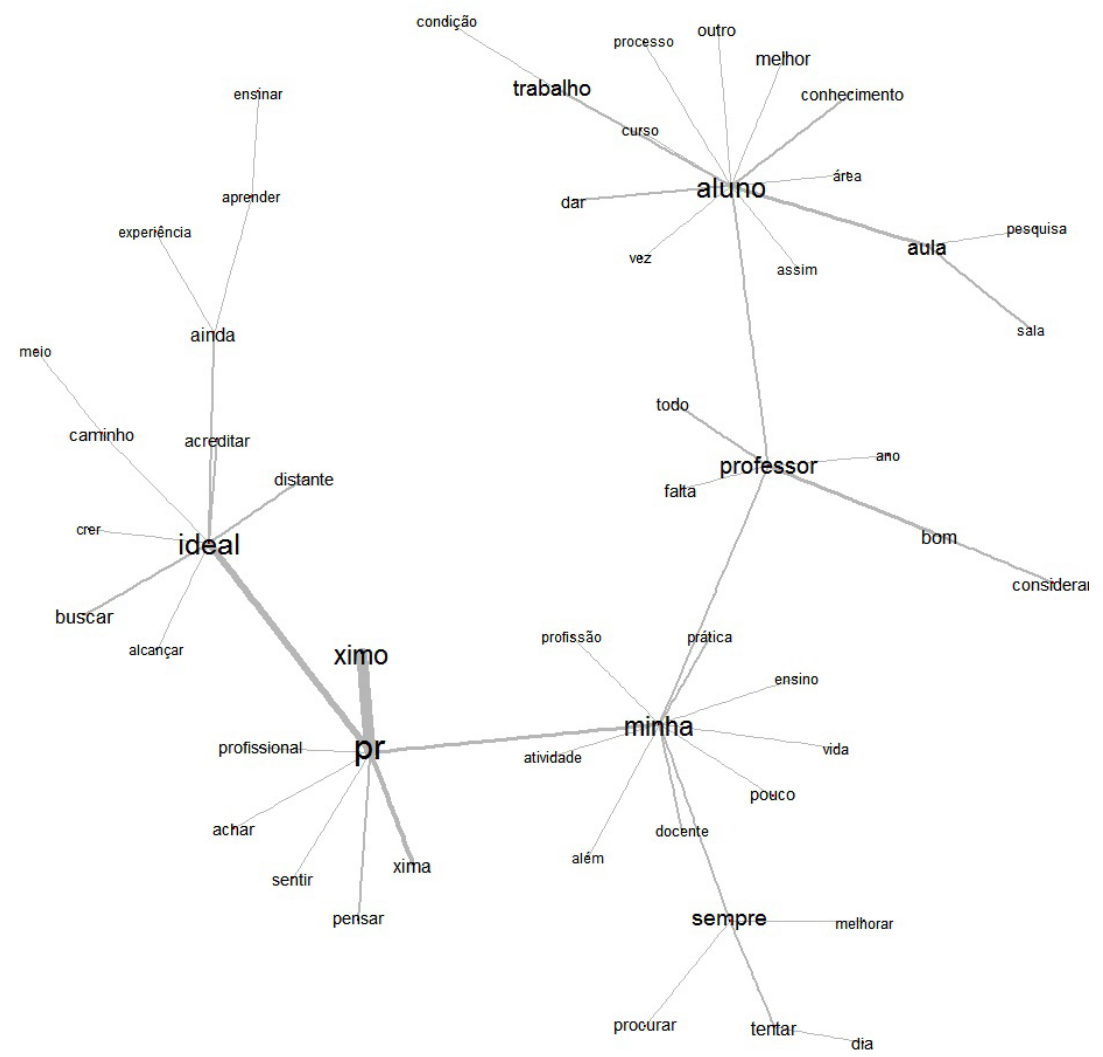

Figura 2. Percepção sobre as próprias virtudes em professores universitários.

Nesta figura, existe uma conexão mais forte entre os troncos de similitudes das palavras-chave: a) ideal e próximo(a) e b) aluno e professor. São relações estabelecidas separadamente, mas que caracterizam o tema central.

A palavra-chave ideal revelou palavras como "acreditar", "buscar", "meio", "caminho" e "distante", apresentando uma relação forte com a palavra-chave próximo (a) e as palavras "profissional", "achar", "sentir" e "pensar". Também apresentou uma relação direta com a palavra-chave minha e palavras como "profissão", "prática", "ensino", "atividade" e "vida". O ideal foi revelado a partir das seguintes falas: "Acredito estar próxima deste ideal, entretanto, ainda acredito que precise de mais experiência e tempo para me dedicar aos estudos." (Part. 102, sexo fem., univ. particular, 25 anos); "Estou no caminho. Como em qualquer caminhada, eu oscilo. Tenho me esforçado para atingir um grau de consciência maior e, assim, ter mais firmeza na minha proposta docente." (Part. 130, sexo masc., univ. pública, 41 anos); "Considero que estou bem próxima deste ideal. Apesar da necessidade de capacitação pedagógica ser permanente ..." (Part. 158, sexo fem., univ. pública, 47 anos).

A conexão das palavras-chave aluno e professor foi formada pela união entre seus respectivos troncos de similitude. $\mathrm{O}$ grupo de palavras referente à palavra aluno, con- tinha palavras como "trabalho/curso/condição", "aula/pesquisa/sala", "processo", "conhecimento" e "área". Já o grupo de palavras relacionado à palavra professor era constituído pelas palavras "todo", "ano", "falta", "bom/considerar". Tanto no tema "Virtudes do bom professor", quanto no tema "Percepção sobre as próprias virtudes em professores universitários", as palavras-chave aluno e professor apareceram como pontos relevantes e mais comentados nas respostas.

Para contemplar a ligação entre estes dois grupos de palavras, são apresentados os recortes a seguir: "... saber se relacionar com os estudantes, tratando-os com respeito, justiça, cortesia, e entender que as pessoas são diferentes e, portanto absorvem o conteúdo e reagem de forma diferente, ser sensível a essas diferenças e saber se comunicar com cada tipo de estudante" (Part. 95, sexo fem., univ. pública, 29 anos); "Sou considerado um bom professor na minha instituição, mas ainda acho que me falta um perfil de educador, me falta contato visual com os alunos, me falta saber os nomes dos alunos em todas as classes" (Part. 114, sexo masc., univ. pública, 61 anos); "Procuro sempre motivar meus alunos, ser compreensiva e ajudá-los quando passam por problemas na vida pessoal e profissional" (Part. 123, sexo fem., univ. particular, 27 anos). 


\section{Discussão}

O objetivo deste estudo foi identificar, nas falas de professores universitários, as características consideradas mais importantes para ser um bom professor de ensino superior. Tais resultados foram discutidos, principalmente, com base na abordagem das virtudes e forças de caráter proposta por Peterson e Seligman (2004).

No tema "Virtudes do bom professor", a característica mais citada diretamente pelos professores foi conhecimento, acompanhada por palavras como aprender, aprendizado, atualizar e estudar. Apresentou sua principal ligação com a palavra-chave aluno, sendo utilizada para expressar a importância da aquisição ou uso do conhecimento como característica marcante de um bom professor. Nesse aspecto, o professor parece representar um papel duplo, sendo caracterizado simultaneamente como mestre e aprendiz.

Os participantes relataram a relevância do nível de conhecimento, das ferramentas didáticas de ensino, e da capacidade de aprendizagem dos docentes para a realização de um trabalho com qualidade. Estes dados corroboram dados de pesquisas sobre a percepção do professor ideal (Komarraju, 2013; Arnon \& Reichel, 2007), em que foram observadas a valorização do conhecimento sobre o tema ensinadoe a didática para ensiná-lo dentre as principais características desejáveis para a docência. A importância do conhecimento é enfatizada pela virtude sabedoria (Peterson \& Seligman, 2004).

A segunda classe de forças de caráter mais citada pelos participantes corresponde à palavra-chave dedicação, que foi ligada à palavra-chave aluno, e acompanhada de palavras como humildade e paciência. Na classificação das forças de caráter (Peterson \& Seligman, 2004) estes termos referem-se à virtude da temperança. Tal grupo de forças indica a proteção contra os excessos e a busca por equilíbrio. Aqui, o bom professor ocuparia um papel de atenção e cuidado no relacionamento com os estudantes, revelando a imagem da docência como um dom, e do professor como aquele que deve ser dedicado e disponível às demandas externas. Komarraju (2013), aponta que as atitudes de cuidado, incentivo e compaixão por parte do docente, configuram-se como motivações extrínsecas dos estudantes para as atividades acadêmicas.

Por outro lado, as palavras-chave bom e trabalho, conectadas através dos respectivos troncos de similitude, refletem as demandas dos professores universitários em relação às instituições de ensino, principalmente de trabaIho. De acordo com Noronha, Delforno e Pinto (2014), as condições de trabalho, que incluem a carga horária e o plano de carreirano que se refere às condições, por exemplo, são um importante fator de influência para a vivência de afetos positivos nas atividades docentes.

Neste quesito foi enfocada a importância da cidadania e do respeito no exercício da prática docente, assim como a dimensão social de responsabilidade atribuída à profissão, remetendo a outra virtude, denominada justiça. Peterson e Seligman (2004) afirmam que os caminhos para alcançar esta virtude são a cidadania, a equidade e a liderança. Tais forças de caráter podem ser exercitadas a partir da dedicação ao trabalho em grupo, da prática da imparcialidade (não permitindo privilégios quando em posição de liderança) e através da responsabilidade pelo sucesso de atividades diversificadas (Seligman, 2004). Além disso, de modo mais geral, o exercíco das forças de caráter influencia na qualidade das atividades profissionais (Harzer \& Ruch, 2013), e por isso, torna-se relevante compreender o quanto os professores acreditam possuí-las.

Com relação à percepção sobre as próprias virtudes, as palavras-chave ideal e próximo foram conectadas demonstrando a maneira como os participantes se localizaram dentro das virtudes associadas à docência. Na maior parte das respostas, ficou evidente a tentativa de alcançar as características valorizadas em um bom professor, da mesma forma que, na maioria dos casos, os entrevistados mostraram-se relativamente satisfeitos e otimistas sobre o seu próprio desempenho profissional.

Observa-se que as palavras-chave ideal e próximo, em um conjunto de respostas, estão próximas das palavras acreditar, buscar e caminho, ligando-se à virtude temperança, pois diz respeito à disciplina para vencer obstáculos e a auto-regulação necessária para tanto (Peterson \& Seligman, 2004). A característica da moderação se refere à expressão de apetites e desejos de forma refletida, sem reprimir as próprias vontades, mas considerando a oportunidade adequada para satisfazê-las (Seligman, 2004).

Verifica-se, contudo, que algumas respostas continham as palavras ideal e próximo com sentido negativo, ressaltando o quanto os participantes não se sentiam próximos ao ideal, ou ainda, distantes dessa possibilidade. Além disso, a relação ideal e próximo também foi utilizada para avaliar as práticas institucionais e condições de trabalho nas universidades públicas e particulares. Em geral, os professores se queixaram da falta de estrutura oferecida nos espaços de ensino, da falta de preparo e maturidade dos alunos que ingressam na graduação, da sobrecarga de trabalho e acúmulo de funções ocupacionais. Nesse caso, as condições de trabalho são ressaltadas como um dos aspectos relevantes no cotidiano da profissão docente, uma vez que aparecem em vários momentos das respostas.

Em contraponto aos problemas mais citados pelos participantes, o grupo de palavras profissão, prática, ensino, atividade e vida, ligado à palavra-chave minha e ao tronco de similitude das palavras-chave ideal e próximo, foi empregado com conotação positiva, apresentando conteúdos como vocação profissional, ou o exercício da atividade que nasceu para fazer, a busca de sentido de vida e o senso de realização. De tal forma, fica refletida a virtude da transcendência, que se refere à capacidade para se conectar a algo maior do que si mesmo, abrindo a possibilidade para a realização pessoal (Peterson \& Seligman, 2004). Nesse caso, pode-se inferir que o sentido de vida ajuda a lidar com as dificuldades vivenciadas no ambiente de trabalho (Silva \& cols., 2009), assim como a busca pela excelência profissional ajuda a promover o aumento de vivências positivas (Noronha \& cols., 2014). 
Cabe sublinhar que por comparação, entre o primeiro e o segundo gráfico, nota-se que duas palavras amplamente valorizadas e repetidas no primeiro não aparecem no segundo: atualizar e estudar. Tal fato pode ser explicado pelo discurso de que a atualização profissional é importante para a constante reciclagem dos docentes, mas que para muitos, ainda não é uma realidade. Fala-se do estudo como uma característica determinante do bom professor, contudo, esta prática não é citada quando pergunta-se sobre o cotidiano dos profissionais.

Os elementos gráficos evidenciaram quais os anseios dos docentes quando trata-se dos temas relativos ao aprimoramento profissional e suas perspectivas de crescimento na carreira. Este conjunto de dados revela as virtudes que os professores universitários pesquisados acreditam apresentar com maior facilidade, tendo sido provavelmente mais desenvolvidas durante sua vida acadêmica.

Como pôde ser observado nas Figuras 1 e 2, as palavras-chave aluno e professor aparecem em destaque nos gráficos, configurando a relação fundamental na qual emergem as virtudes do bom professor. Tal dimensão também apareceu na ligação forte entre os troncos de similitude dessas duas palavras-chave a partir da palavra relação (Figura 1), demonstrando que para caracterizar quem é o bom professor, torna-se importante considerar o impacto desse profissional na vida dos alunos.

Isso refletiu a valorização do relacionamento interpessoal pelos entrevistados e a importância dada ao estabelecimento de vínculos afetivos para a apreensão dos conteúdos acadêmicos. A característica que se refere ao bom relacionamento interpessoal dentro do conjunto de virtudes proposto por Peterson e Seligman (2004) é a humanidade. A Psicologia Positiva considera a possibilidade de relacionamentos ativos e construtivos através de forças como amor, gentileza e inteligência social, consideradas importantes para a valorização de relacionamentos próximos e responsáveis pelo coeficiente de inteligência emocional (Snyder \& Lopez, 2009).

A partir da proposta de investigação das virtudes do bom professor, foram identificados elementos que apontam a valorização do conhecimento, temperança, justiça, transcendência, e humanidade. Todavia, na amostra estudada, a valorização da virtude coragem mostrou-se fragmentada, e não constituiu a proporção mais citada pelos participantes. Este fato deve ser sublinhado, pois a virtude coragem diz respeito ao enfrentamento de adversidades, de maneira mais aberta e consciente (Peterson \& Seligman, 2004).

Nesse sentido, o professor ideal foi delineado como aquele que apresenta, principalmente: a) conhecimento, virtudes para ensinar e aprender, com segurança e domínio dos conteúdos que leciona; b) temperança, virtudes para a auto-regulação, com destaque para a paciência e a humildade no desenvolvimento de suas atividades; c) justiça, virtudes para realizar atividades cívicas, valorizando a equidade e a dimensão social da profissão; e d) humanidade, virtudes para construir relacionamentos interpessoais positivos no ambiente de trabalho. No que se refere à percepção dos professores acerca de suas próprias virtudes, três foram citadas com maior freqüência pelos participantes: a) temperança, e as virtudes necessárias para a busca do equilíbrio pessoal, b) transcendência, e as virtudes para a busca de sentido de vida, e c) humanidade, virtudes para a interação social positiva.

Como proposto no trabalho de McGovern e Miller (2008), o uso de um sistema de classificação das forças de caráter poderia oferecer uma forma inovadora de desenvolvimento de competências, pois auxiliaria os professores a refletirem mais sobre suas estratégias de ensino e aprendizagem. Além disso, poderia facilitar a percepção do nível de gratificação com seu trabalho.

\section{Considerações Finais}

Este estudo buscou compreender as virtudes valorizadas pelos professores universitários acerca de sua própria profissão. As virtudes mais valorizadas pelos participantes foram conhecimento, temperança, justiça, e humanidade, enquanto aquelas virtudes que mais acreditavam possuir foram temperança, humanidade e transcendência. Tais resultados ajudam a pensar nas habilidades e competências exigidas na vida acadêmica, que referem-se ao grupo de virtudes mais valorizadas pelos participantes, assim como as virtudes percebidas de fato em suas atividades profissionais, e que acreditam possuir.

Propostas de programas de intervenção para professores universitários podem ser baseadas no treinamento e exercício das virtudes no ambiente de trabalho. O foco sugerido é a adoção da abordagem das virtudes no desenvolvimento de estratégias de enfrentamento, mas principalmente, como fator de aumento dos afetos positivos e do bem-estar geral no ambiente de trabalho.

Algumas observações sobre a realização da pesquisa como um todo, incluindo os dois estudos aqui apresentados, tornam-se relevantes para compreender os limites dos achados. Os questionários foram encaminhados por e-mail para centenas de professores do Brasil inteiro, mas a amostra se restringiu a 214 participantes devido ao baixo nível de retorno. Dentre eles, poucos eram oriundos das regiões Centro-Oeste, Sul, Norte e Nordeste, sendo que a maioria, $63,6 \%$, residia na região Sudeste. Na presente amostra, $73,8 \%$ dos docentes trabalhavam em universidades públicas, enquanto apenas $37,4 \%$ atuavam em universidades particulares. Com base nas limitações percebidas, pesquisas futuras deveriam expandir a amostra para outras regiões do país e para professores de universidades particulares, de forma a perceber se culturas regionais e organizacionais diferenciadas podem influenciar a percepção/utilização das virtudes e forças de caráter.

\section{Referências}

Amparo, D. M., Galvão, A. C. T., Cardenas, C., \& Koller, S. H. (2008). A escola e as perspectivas educacionais de jovens em situação de risco. Psicologia Escolar e Educacional, 12(1), 69-88. 
Araújo, T. M., Graça, C. C., \& Araújo, E. (2003). Estresse ocupacional e saúde: contribuições do Modelo Demanda-Controle. Ciência \& Saúde Coletiva, 8(4), 991-1003.

Arendt, H. (2007). A condição humana. 10.ed. Rio de Janeiro: Forense Universitária.

Arnon, S. \& Reichel, N. (2007). Who is the ideal teacher? Am I? Similarity and difference in perception of students of education regarding the qualities of a good teacher and of their own qualities as teachers. Teachers and Teaching: Theory and Practice, 13(5), 441-464.

Camargo, B. V. \& Justo, A. M. (2013). IRAMUTEQ: um software gratuito para análise de dados textuais. Temas em Psicologia, 21(2), 513518.

Dell'Aglio, D. D., Koller, S. H., \& Yunes, M. A. M. (2011). Resiliência e psicologia positiva: interfaces do risco à proteção. São Paulo: Casa do Psicólogo.

Freitas, H., Janissek-Muniz, R., \& Moscarola, J. (2004). Uso da Internet no processo de pesquisa e análise de dados. Associação Nacional de Empresas de Pesquisa. São Paulo: ANEP. Recuperado: 10 mai. 2016. Disponível: http://www.lume.ufrgs.br/bitstream/ handle/10183/4801/000504797.pdf.

Gander, F., Proyer, R. T., Ruch, W., \& Wyss, T. (2012). The good character at work: An initial study on the contribution of character strengths in identifying healthy and unhealthy work-related behavior and experience patterns. International archives of occupational and environmental health, 85(8), 895-904.

Garcia, L. P. \& Benevides-Pereira, A. M. T. (2003). Investigando - Burnout em professores universitários. InterAçãoPsy Maringá,1(1),76-89.

Hakanen, J. J., Bakker, A. B., \& Schaufeli, W. B. (2006). Burnout and work engagement among teachers. Journal of school psychology,43(6), 495-513.

Harzer, C. \& Ruch, W. (2013). The application of signature character strengths and positive experiences at work. Journal of Happiness Studies, 14(3), 965-983.

Horn, J. E., Taris, T. W., Schaufeli, W. B., \& Schreurs, P. J. (2004). The structure of occupational well-being: Astudy among Dutch teachers. Journal of occupational and Organizational Psychology,77(3), 365375 .

Keeley, J., Smith, D., \& Buskist, W. (2006). The Teacher Behaviors Checklist: Factor analysis of its utility for evaluating teaching. Teaching of Psychology, 33, 84-91.

Komarraju, M. (2013). Ideal teacher behaviors student motivation and self-efficacy predict preferences. Teaching of Psychology, 40(2), 104-110.
McGovern, T. V. \& Miller, S. L. (2008). Integrating teacher behaviors with character strengths and virtues for faculty development. Teaching of Psychology, 35(4), 278-285.

Neto, L. M. \& Marujo, H. Á. (2012). Propostas estratégicas da Psicologia Positiva para a prevenção e regulação do stress. Análise Psicológica, 25(4), 585-593.

Noronha, A. P. P., Delforno, M. P., \& Pinto, L. P. (2014). Afetos positivos e negativos em professores de diferentes níveis de ensino. Psicologia Escolar e Educacional, 18(2), 211-218.

Paludo, S. \& Koller, S. H. (2007). Psicologia positiva: Uma nova abordagem para antigas questões. Paidéia, 17(36), 9-20.

Peterson, C. \& Seligman, M. E. (2004). Character strengths and virtues: A handbook and classification. Oxford University Press.

Pocinho, M. \& Perestrelo, C. X. (2011). Um ensaio sobre burnout, engagement e estratégias de coping na profissão docente. Educação e Pesquisa, 37, 513-528.

Pureza, J. D. R., Kuhn, C. H. C., Castro, E. K. D., \& Lisboa, C. S. D. M. (2012). Psicologia positiva no Brasil: uma revisão sistemática da literatura. Revista Brasileira de Terapias Cognitivas, 8(2), 109-117.

Ratinaud, P. (2009). IRAMUTEQ: Interface de R pour les Analyses Multidimensionnelles de Textes et de Questionnaires [Computer software]. Disponível: http://www.iramuteq.org.

Ratinaud, P. \& Marchand, P. (2012). Application de la méthode ALCESTE à de "gros" corpus et stabilité des "mondes lexicaux": analysedu "Cable-Gate" avec IraMuTeQ. Em Actes des 11 eme Journées internationales d'Analyse statistique des DonnéesTextuelles (pp. 835-844). Liège, Belgique.

Rocha, K. B. \& Sarriera, J. C. (2006). Saúde percebida em professores universitários: Gênero, religião e condições de trabalho.Psicologia Escolar e Educacional,10(2), 187-196.

Seligman, M. E. P. (2004). Felicidade autêntica: Os princípios da psicologia positiva. (Editora Pergaminho SA, trad.). Nova lorque: Free Press.

Seligman, M. E. \& Csikszentmihalyi, M. (2000). Positive psychology: An introduction, American Psychologist, 55 (1), 5.

Silva, J. P. D., Damásio, B. F., \& Melo, S. A. (2009). O sentido de vida e o estresse do professorado: Um estudo correlacional. Cadernos de Psicologia Social do Trabalho, 12(1), 111-122.

Snyder, C. R. \& Lopez, S. J. (2009). Psicologia Positiva: Uma abordagem científica e prática das qualidades humanas (R. C. Costa, Trad.). Porto Alegre: Artmed.

Sousa, I. F. \& Mendonça, H. (2009). Burnout em professores universitários: impacto de percepções de justiça e comprometimento 
afetivo. Psicologia: Teoria e Pesquisa, 25(4), 499-508.

Wachelke, J. \& Wolter, R. (2011). Critérios de construção e relato da análise prototípica para representações sociais. Psicologia: Teoria e Pesquisa, 27(4), 521-526.
Wood, A. M., Linley, P. A., Maltby, J., Kashdan, T. B., \& Hurling, R. (2011). Using personal and psychological strengths leads to increases in well-being over time: A longitudinal study and the development of the strengths use questionnaire. Personalityand Individual Differences, 50(1), 15-19.

Recebido em: 16/06/2016

Aprovado em: 29/11//2016

\section{Sobre as autoras}

Marcella Bastos Cacciari (marcella.cacciari@gmail.com)

Mestrado em Psicologia pela Universidade Federal do Espírito Santo (2015),

Coordenadora do Curso de Psicologia da Faculdade Multivix - São Mateus - ES.

Valeschka Martins Guerra (valeschka.guerra@ufes.br)

Orientador de Mestrado, Orientador de Doutorado. Doutorado em Social Psychology pela University of Kent, Inglaterra (2009). Professor adjunto da Universidade Federal do Espírito Santo- ES.

Priscilla de Oliveira Martins-Silva (priscillamartinssilva@gmail.com)

Doutorado em Psicologia pela Universidade Federal do Espírito Santo (2009), Professora da Universidade Federal do Espírito Santo - ES.

Clarisse Lourenço Cintra (clarisselc@gmail.com)

Mestrado em Psicologia pela Universidade Federal do Espírito Santo (2016). Coordenação de educação e projetos do Grupo de Estudos e Práticas em Psicologia Positiva.

Naiara Ferreira Vieira Castello (naiaracastello@gmail.com)

Graduação em Psicologia pela Universidade Federal do Espírito Santo, Brasil (2015). Estudante do Grupo de Estudos e Pesquisas em Sexualidades.

A presente pesquisa contou com o apoio da CAPES por meio da bolsa de Mestrado concedida à primeira autora. As autoras agradecem a esta instituição. Trabalho derivado de dissertação de mestrado da primeira autora. 